\title{
Immunoreactive cell wall proteins of Clostridium difficile identified by human sera
}

\author{
Correspondence \\ Neil F. Fairweather \\ n.fairweather@imperial.ac.uk
}

Received 24 July 2007

Accepted 19 October 2007

\author{
Anne Wright, ${ }^{1}$ Denise Drudy, ${ }^{2}$ Lorraine Kyne, ${ }^{3}$ Katherine Brown ${ }^{1}$ \\ and Neil F. Fairweather ${ }^{1}$ \\ ${ }^{1}$ Centre for Molecular Microbiology and Infection, Division of Cell and Molecular Biology, \\ Imperial College, London SW7 2AZ, UK \\ ${ }^{2}$ Centre for Food Safety, School of Agriculture, Food Science and Veterinary Medicine, \\ University College Dublin, Belfield, Dublin 4, Ireland \\ ${ }^{3}$ Department of Medicine for the Older Person, Mater Misericordiae University Hospital, Dublin 7 , \\ Ireland
}

\begin{abstract}
Clostridium difficile is a leading cause of nosocomial infection in the developed world, causing antibiotic-associated disease in susceptible populations. The identity of immunogenic proteins is important in understanding the pathogenesis of disease and in the design of vaccines. This study analysed the sera of six patients infected during a hospital outbreak of a $C$. difficile ribotype 017 strain. Using a proteomics-based approach, cell wall proteins were separated by two-dimensional PAGE, and immunoreactive proteins were revealed by reaction with patient sera. The identity of immunoreactive proteins was established by MS. Forty-two different proteins were identified in total. All patient sera reacted with at least one component of the surface-layer protein (SLP), four reacted with both components (high- and low-molecular-mass SLPs), and five reacted with one other cell wall protein, suggesting that these are immunodominant antigens. The role of these proteins as potential vaccine candidates and their roles in pathogenesis deserve further study.
\end{abstract}

\section{INTRODUCTION}

Clostridium difficile-associated disease (CDAD) is now a major health problem in the developed world, and is the most common cause of nosocomial infectious diarrhoea in many hospitals (Bartlett, 2007; Cloud \& Kelly, 2007). The main virulence factors of the bacterium are the toxins $A$ (TcdA) and B (TcdB), which are expressed by the bacterium in the gastrointestinal tract. These toxins mediate destruction of the integrity of the epithelial cell barrier and induce a variety of physiological effects on intestinal cells (Just \& Gerhard, 2004; Poxton et al., 2001; Voth \& Ballard, 2005). In order to produce toxins in the gut, $C$. difficile must colonize the enteric tissues and survive the many pressures to eliminate micro-organisms that compete with the normal flora. However, the bacterial proteins mediating colonization, adhesion to host cells and evasion of the immune responses remain to be identified

Abbreviations: 2DE, two-dimensional PAGE; CDAD, Clostridium difficileassociated disease; ECL, enhanced chemiluminescence; HRP, horseradish peroxidase; IPG, immobilized $\mathrm{pH}$ gradient; MALDI, matrixassociated laser desorption/ionization; MS/MS, tandem mass spectrometry; SLP, surface-layer protein.

The complete dataset of immunoreactive proteins identified in this study is available as supplementary data with the online version of this paper. and characterized fully. Potential candidate proteins for these activities include the surface-layer proteins (SLPs) (Calabi et al., 2001), flagella (Tasteyre et al., 2000), the chaperone GroEL (Hennequin et al., 2001), the fibronectin-binding proteins (Hennequin et al., 2003) and the adhesion protein Cwp66 (Waligora et al., 2001).

One approach to the identification of such proteins is to examine the human immune response to bacterial infection. This not only provides information about the expression of proteins in the host, but also may serve to identify proteins involved in pathogenesis. A number of studies have examined the human immune response to specific surface components of $C$. difficile. The flagellar proteins FliC and FliD, and the surface-associated proteins Cwp66 and Cwp84, were found to be expressed during the course of an infection, as shown by their reactivity with patient sera (Pechine et al., 2005). In a study involving 146 patients (55 patients with CDAD, 34 asymptomatic carriers and 57 controls), the responses to the SLPs was investigated (Drudy et al., 2004). No significant difference in the serum IgM, IgA or IgG antibody levels among cases, carriers or control groups was found. However, patients that suffered multiple-relapsing infections were shown to have significantly lower IgM anti-SLP levels than single-episode patients (Drudy et al., 2004). 
Identification of $C$. difficile proteins that are immunoreactive in humans will aid our understanding of the immune response to infection. In this study, we used proteomics tools to identify several $C$. difficile proteins recognized by the human immune system during CDAD infection.

\section{METHODS}

Bacterial strains and culture conditions. C. difficile M9 (PCR ribotype 017 , toxin $\mathrm{A}^{+} / \mathrm{B}^{-}$) was isolated following an outbreak in Mater Misericordiae University Hospital (Drudy et al., 2006). C. difficile was grown on blood agar plates or in brain heart infusion broth at $37^{\circ} \mathrm{C}$ in a Don Whitley anaerobic cabinet in an atmosphere of $10 \% \mathrm{CO}_{2}, 10 \% \mathrm{H}_{2}$ and $80 \% \mathrm{~N}_{2}$.

Serum samples. Stored sera from an ongoing prospective investigation into the molecular epidemiology of $C$. difficile at the Mater Misericordiae University Hospital was used and was approved by the local regional ethical committee. Antiserum was collected on days 1 and 12 of confirmed $C$. difficile infection from patients with a single episode of $C$. difficile diarrhoea $\operatorname{CDAD}(n=4)$ and from patients with recurrent episodes of $C$. difficile diarrhoea $(n=2)$.

Preparation of protein extracts from $\boldsymbol{C}$. difficile. SLPs and cell wall proteins were extracted as described previously (Wright et al., 2005). Briefly, the SLPs were extracted by resuspending a bacterial pellet in $0.04 \mathrm{M}$ glycine ( $\mathrm{pH} 2.2$ ). After incubation for $30 \mathrm{~min}$ at room temperature, intact cells were centrifuged $(5 \mathrm{~min}$ at $10000 \mathrm{~g}$ ) and the supernatant neutralized to $\mathrm{pH} 7.0$ with $2 \mathrm{M}$ Tris/HCl. For the preparation of cell wall proteins, a $24 \mathrm{~h}$ bacterial culture was pelleted by centrifugation (31600 $\mathrm{g}$ for $3 \mathrm{~min}$ ). Bacterial pellets were washed once in PBS and once in TS buffer $[10 \mathrm{mM}$ Tris/HCl ( $\mathrm{pH} 6.9$ ), $10 \mathrm{mM} \mathrm{MgCl}, 0.5 \mathrm{M}$ sucrose]. The pellets were resuspended in $2 \mathrm{ml}$ TS containing $60 \mu \mathrm{g}$ mutanolysin $\mathrm{ml}^{-1}, 1 \mu \mathrm{g}$ lysozyme $\mathrm{ml}^{-1}, 50 \mu \mathrm{g}$ lysostaphin $\mathrm{ml}^{-1}, 250 \mu \mathrm{g}$ RNase $\mathrm{A} \mathrm{ml}^{-1}$ and $2 \mathrm{mM} \mathrm{4-(2-ami-}$ noethyl)benzenesulfonyl fluoride hydrochloride, and incubated for $2 \mathrm{~h}$ at $37{ }^{\circ} \mathrm{C}$ with gentle rotating agitation. After checking for lysis by phase-contrast microscopy, cells were pelleted by centrifugation at $16700 \mathrm{~g}$ for $5 \mathrm{~min}$. Supernatant fluids containing cell wall-associated proteins were collected, filtered and stored at $4{ }^{\circ} \mathrm{C}$.

ELISA. ELISA titres were determined essentially as described previously (Qazi et al., 2006). Briefly, ELISA plates were coated with $50 \mu \mathrm{l}$ cell wall proteins (approx. $1 \mu \mathrm{g} \mathrm{ml}{ }^{-1}$ in carbonate buffer, $\mathrm{pH}$ 9.6) isolated from strain M9. After incubation overnight at $4{ }^{\circ} \mathrm{C}$, plates were washed with PBS containing $0.05 \%$ Tween 20 and blocked by the addition of $2 \%$ BSA. Test antisera were diluted in PBS containing $2 \%$ BSA, $0.05 \%$ Tween 20 , added to the plate and incubated for $1 \mathrm{~h}$ at $37^{\circ} \mathrm{C}$. After washing as above, secondary antibody [1:1000 dilution of horseradish peroxidase (HRP)-conjugated goat anti-human IgG, IgA and IgM; Sigma] was added and incubated for $1 \mathrm{~h}$. After washing, HRP activity was measured at $A_{492}$. A dilution of serum that gave an $A_{492}$ value of 0.2 above the level measured in pre-immune samples was considered to be positive. Standardization of the results was made possible by the inclusion on each plate of a control serum of known titre.

Two-dimensional PAGE (2DE), trypsin digestion and MS. Protein concentrations were measured using a 2-D Quant kit (Amersham Biosciences) following the manufacturer's instructions. Immobilized $\mathrm{pH}$ gradient (IPG) strips with a non-linear $\mathrm{pH}$ range from 3 to 10 (Bio-Rad) were rehydrated in a solution of $8 \mathrm{M}$ urea, $2 \%$ (w/v) CHAPS, $0.5 \%$ (v/v) IPG buffer (Bio-Rad), $0.05 \%$ bromophenol blue and $1 \mathrm{mM}$ DTT. Protein samples $(50 \mu \mathrm{g})$ were cup-loaded onto the IPG strips during isoelectric focusing using an IPGphor (Pharmacia). Proteins were subjected to isoelectric focusing for a minimum of $14 \mathrm{kVh}$. Following isoelectric focusing, the IPG strips were equilibrated in $50 \mathrm{mM}$ Tris/ $\mathrm{HCl}$ ( $\mathrm{pH} 8.8$ ), $6 \mathrm{M}$ urea, $30 \%$ $(\mathrm{v} / \mathrm{v})$ glycerol, $10 \mathrm{mg} \mathrm{DTT} \mathrm{ml}^{-1}$, and embedded in agarose on the top of a 4-12\% gradient acrylamide gel. SDS-PAGE was then carried out using a Criterion system (Bio-Rad) at $150 \mathrm{~V}$ for $40 \mathrm{~min}$. Protein gels were stained with colloidal Coomassie blue.

For identification of proteins, spots were excised from gels and in-gel tryptic digestion was performed after reduction with DTT and $S$ carbamidomethylation with iodoacetamide. Gel pieces were washed three times with $50 \%(\mathrm{v} / \mathrm{v})$ aqueous acetonitrile containing $25 \mathrm{mM}$ ammonium bicarbonate and dried in a vacuum concentrator for $30 \mathrm{~min}$. Sequencing-grade, modified porcine trypsin (Promega) was dissolved in $50 \mathrm{mM}$ acetic acid supplied by the manufacturer and then diluted fivefold by adding $25 \mathrm{mM}$ ammonium bicarbonate to give a final trypsin concentration of $0.02 \mu \mathrm{g} \mu^{-1}$. Gel pieces were rehydrated by adding $10 \mu \mathrm{l}$ trypsin solution and digested overnight at $37{ }^{\circ} \mathrm{C}$.

A $0.5 \mu \mathrm{l}$ aliquot of each digest was applied directly to a matrixassociated laser desorption/ionization (MALDI) target plate, followed immediately by an equal volume of a freshly prepared solution of 4hydroxy- $\alpha$-cyano-cinnamic acid $\left(5 \mathrm{mg} \mathrm{ml}^{-1}\right.$; Sigma) in $50 \%(\mathrm{v} / \mathrm{v})$ aqueous acetonitrile containing $0.1 \%(\mathrm{v} / \mathrm{v})$ trifluoroacetic acid. Positive-ion MALDI mass spectra were obtained using an Applied Biosystems 4700 Proteomics Analyzer in reflectron mode with an accelerating voltage of $20 \mathrm{kV}$. Mass spectra were acquired with a total of 1000 laser pulses over a mass range of $\mathrm{m} / z$ 800-4000. Final mass spectra were the summation of 20 subspectra, each acquired with 50 laser pulses and internally calibrated using the tryptic autoproteolysis products at $\mathrm{m} / \mathrm{z} 842.509$ and 2211.104. Monoisotopic masses were obtained from centroids of raw, unsmoothed data.

For collision-induced dissociation tandem mass spectrometry (MS/ MS), a source 1 accelerating voltage of $8 \mathrm{kV}$, a collision energy of $1 \mathrm{kV}$ and a source 2 accelerating voltage of $15 \mathrm{kV}$ were used. Air was used as the collision gas at the instrument's 'medium' pressure setting with a recharge threshold of $1.3 \times 10^{-4} \mathrm{~Pa}$, which produced a source 2 pressure of about $1.3 \times 10^{-4} \mathrm{~Pa}$. The precursor mass window was set to a relative resolution of 50 , and the metastable suppressor was enabled. The default calibration was used for MS/MS spectra, which were baseline-subtracted (peak width 50) and smoothed (SavitskyGolay method with three points across a peak and polynomial order 4); peak detection used a minimum signal-to-noise ratio of 5 , a local noise window of $50 \mathrm{~m} / z$ and a minimum peak width of 2.9 bins. Filters of signal-to-noise ratio 20 and 10 were used for generating peak lists from MS and MS/MS spectra, respectively.

Mass spectral data obtained in batch mode were submitted to the Mascot database searching program (version 2.1; Matrix Science Ltd) to search the NCBI non-redundant protein database. Batch-acquired MS and MS/MS spectral data were submitted to a combined peptide mass fingerprint and MS/MS ion search through the Applied Biosystems GPS Explorer software interface (version 3.6) to Mascot. Search criteria included: maximum missed cleavages, 1; variable modifications, oxidation (M), carbamidomethyl; peptide tolerance, 100 p.p.m.; MS/MS tolerance, $0.1 \mathrm{Da}$.

Western blotting. Following SDS-PAGE, proteins were electroblotted using a mini Trans-Blot cell (Bio-Rad) onto a nitrocellulose membrane (Bio-Rad) in transfer buffer for $1 \mathrm{~h}$ at $70 \mathrm{~V}$ at $4{ }^{\circ} \mathrm{C}$. Membranes were blocked with $3 \%$ BSA. Triplicate washes using PBS containing $0.1 \%$ Tween (PBS/Tween) were performed after each incubation step for $20 \mathrm{~min}$. Patient antisera were used at a dilution of $1: 500$ in $0.3 \%$ BSA in PBS/Tween. Bound primary antibodies were detected with HRP-conjugated goat anti-rabbit IgG (Dako) or goat 
anti-human IgG, IgA and IgM (Sigma) at a dilution of $1: 2000$ in $0.3 \% \mathrm{BSA}$ in PBS/Tween. Each incubation step was performed for a minimum of $1 \mathrm{~h}$ at room temperature. Blots were developed by enhanced chemiluminescence (ECL; Amersham Biosciences) following the manufacturer's instructions and visualized using a Fuji LAS3000 Imager, using the 'wizard' feature to calculate the optimal development time automatically. MALDI-MS and MS/MS were carried out by the service provided by Jerry Thomas, University of York, UK, using an Applied Biosystems 4700 Proteomics Analyzer.

\section{RESULTS AND DISCUSSION}

\section{Antibody responses to $C$. difficile proteins}

The sera from six patients infected with $C$. difficile strain M9 (PCR ribotype 017, toxin $\mathrm{A}^{+} / \mathrm{B}^{-}$) in the Mater Misericordiae University Hospital, Dublin, were obtained for this study. Four of the patients (patients 1-4) had a single episode of CDAD, whereas the two other patients (patients 5 and 6) experienced recurrent infections. For all patients, serum was obtained on the first day that CDAD was confirmed and again 12 days later. ELISAs were carried out to assess the antibody responses of the patient sera, as well as the antibody responses from a non-infected control individual, to cell wall proteins extracted from $C$. difficile M9. Five out the six patients had low levels of antibodies against cell wall proteins (titres of less than 1000) on days 1 and 12 of infection. The remaining patient had a titre of 800 on day 1 and of 1200 on day 12 (data not shown). The non-infected control individual had a titre of less than 800 .

Proteins were extracted from the $C$. difficile M9 cells in three ways: (i) using low-pH glycine (to yield SLPs); (ii) using lysozyme to yield cell wall proteins; and (iii) using a Bio-Rad commercial extraction kit, to yield whole-cell lysates. These protein fractions were analysed by onedimensional SDS-PAGE. Proteins from replicate gels were transferred to nitrocellulose and probed separately with the sera from the six patients taken at days 1 and 12 . Bound antibodies were detected using a mixture of anti-human IgG, IgA and IgM antibodies conjugated to HRP, in combination with ECL (Fig. 1). All sera reacted with many proteins in all of the cell extracts, showing that $C$. difficile proteins were recognized by components of the immune system of all six patients. In general, the sera taken on day 12 after CDAD confirmation recognized a greater number of proteins than the sera taken on day 1 , suggesting that, during infection, patients were mounting an immune response against proteins they did not recognize at the outset. The antibody response seen in all patients on day 1 of infection was unlikely to be due to the infection diagnosed on that day and may have been the result of a

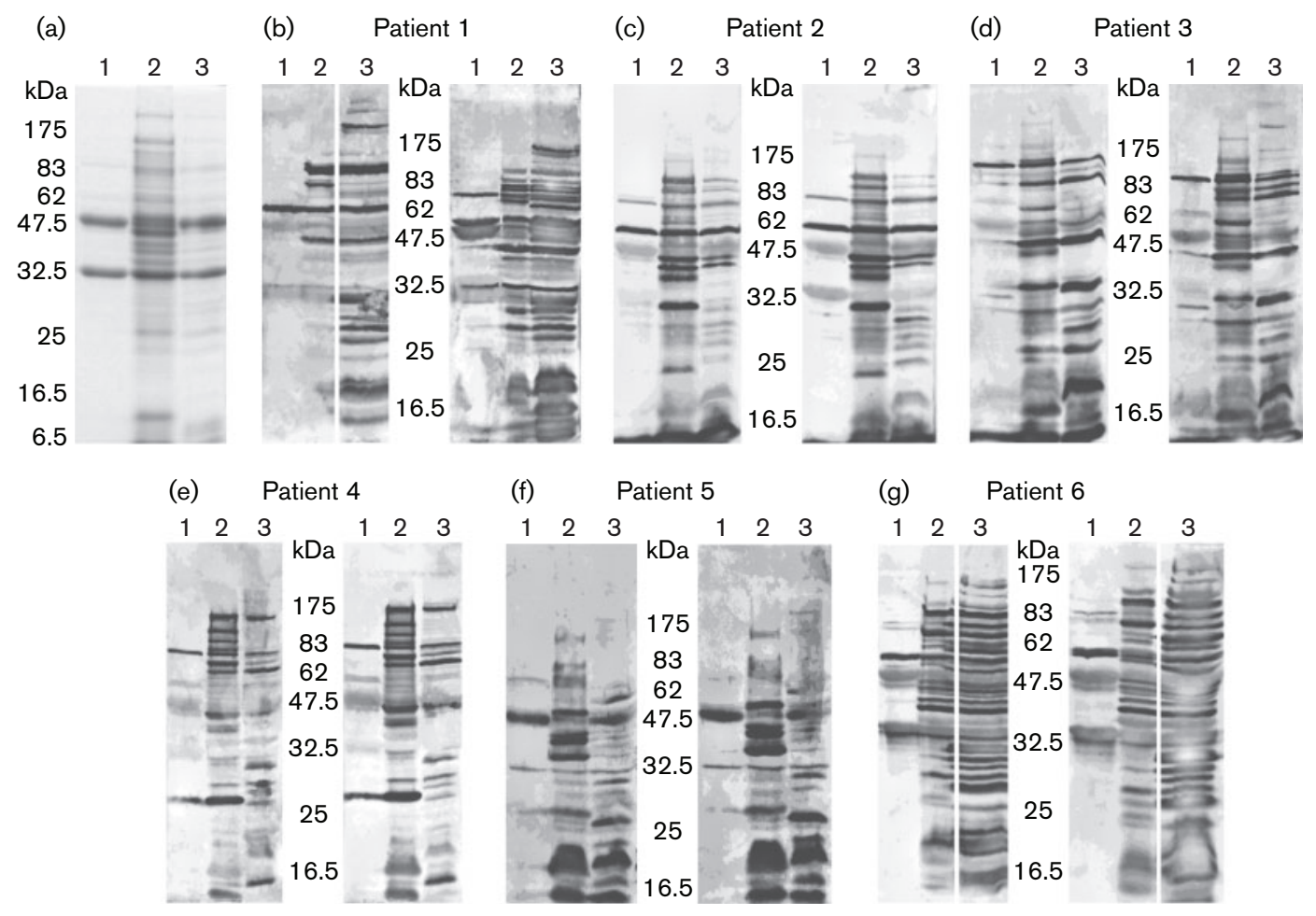

Fig. 1. Analysis of C. difficile proteins by SDS-PAGE and Western blotting using patient sera: (a) proteins stained with Coomassie blue, $(\mathrm{b}-\mathrm{g})$ proteins probed with serum from patients 1-6, respectively. Sera taken from patients on day 1 of infection are shown in the left-hand blot and sera taken on day 12 of infection are shown in the right-hand blot. Patients 5 and 6 experienced recurrent infections. Molecular masses in $\mathrm{kDa}$ are indicated. Proteins were extracted by low-pH glycine treatment for SLP preparation (lane 1), lysozyme treatment for cell wall proteins (lane 2) and sonication for total cell lysate (lane 3 ). 
previous infection or previous asymptomatic colonization with $C$. difficile. There was no discernible qualitative difference between the proteins recognized by the sera of the patients that suffered a single episode of infection (patients 1-4) and those that had relapsing infections (patients 5 and 6).

\section{Identification of $C$. difficile proteins recognized by patient sera}

In order to identify the $C$. difficile proteins recognized by the patient sera, an immunoproteomic approach was taken. C. difficile M9 cell wall proteins were prepared and separated by $2 \mathrm{DE}$. These cell wall preparations contained the major SLPs present in a low-pH glycine extract, together with many other minor cell wall proteins (Wright et al., 2005). Replicate gels were prepared, and the proteins transferred to nitrocellulose membranes and probed with the patient antisera taken on day 12 of infection. Unfortunately, it was not possible to obtain Western blot data from the non-infected control patient. In all cases, the results revealed numerous immunoreactive proteins (Fig. 2). In order to identify as many immunoreactive spots as possible from each patient, each Western blot was overlaid on an image of a gel containing $C$. difficile M9 cell wall proteins stained with Coomassie blue. In many cases, it was possible to identify the protein spots that contained the immunoreactive proteins. Fig. 3 shows the results of (a)

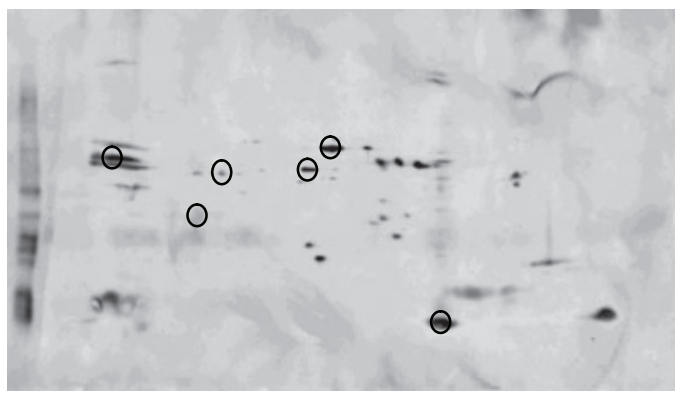

(c)

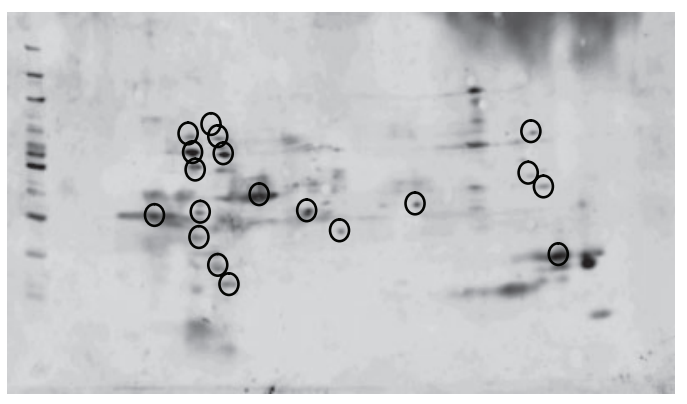

(e)

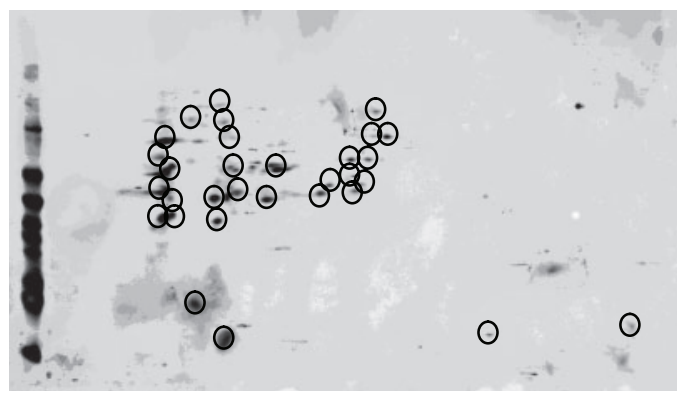

(b)

Patient 2

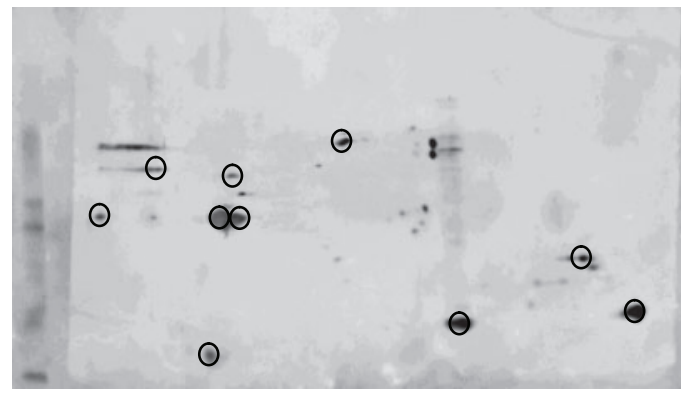

(d)

Patient 4

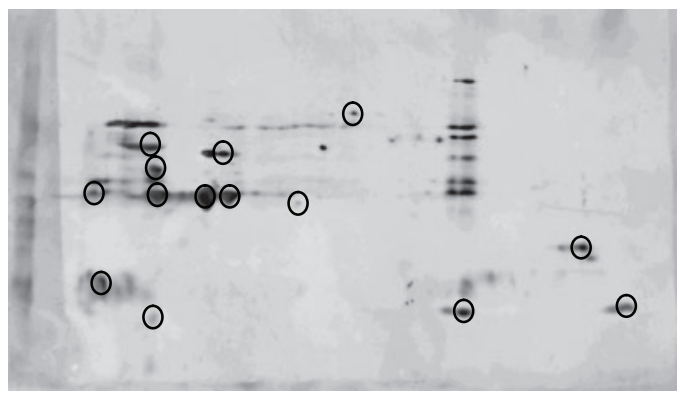

(f)

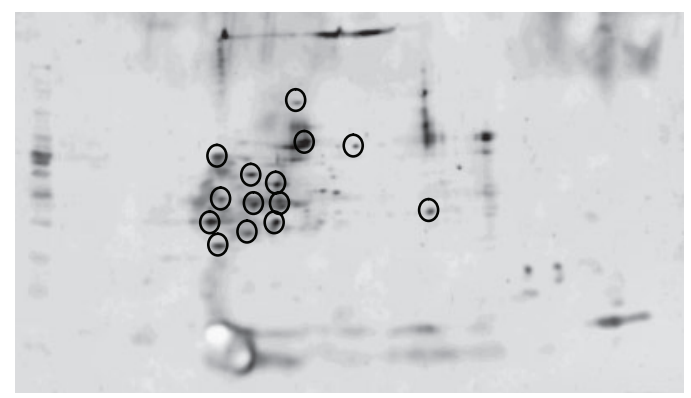

Fig. 2. Cell wall proteins from C. difficile M9 recognized by human patient antisera. Protein $(50 \mu \mathrm{g})$ was separated by $2 \mathrm{DE}$ and Western blots were prepared. Blots were probed with antiserum from the six patients, taken on day 12 of infection. A mixture of goat anti-human $\lg$, IgA and IgM antibodies, conjugated to HRP, was used in combination with ECL to detect the primary antibodies. These blots were compared with replicate gels (Fig. 3) stained by colloidal Coomassie blue and, where possible, immunoreactive proteins were picked for MS/MS analysis (indicated by circles). Patients 5 and 6 experienced recurrent CDAD infections. 


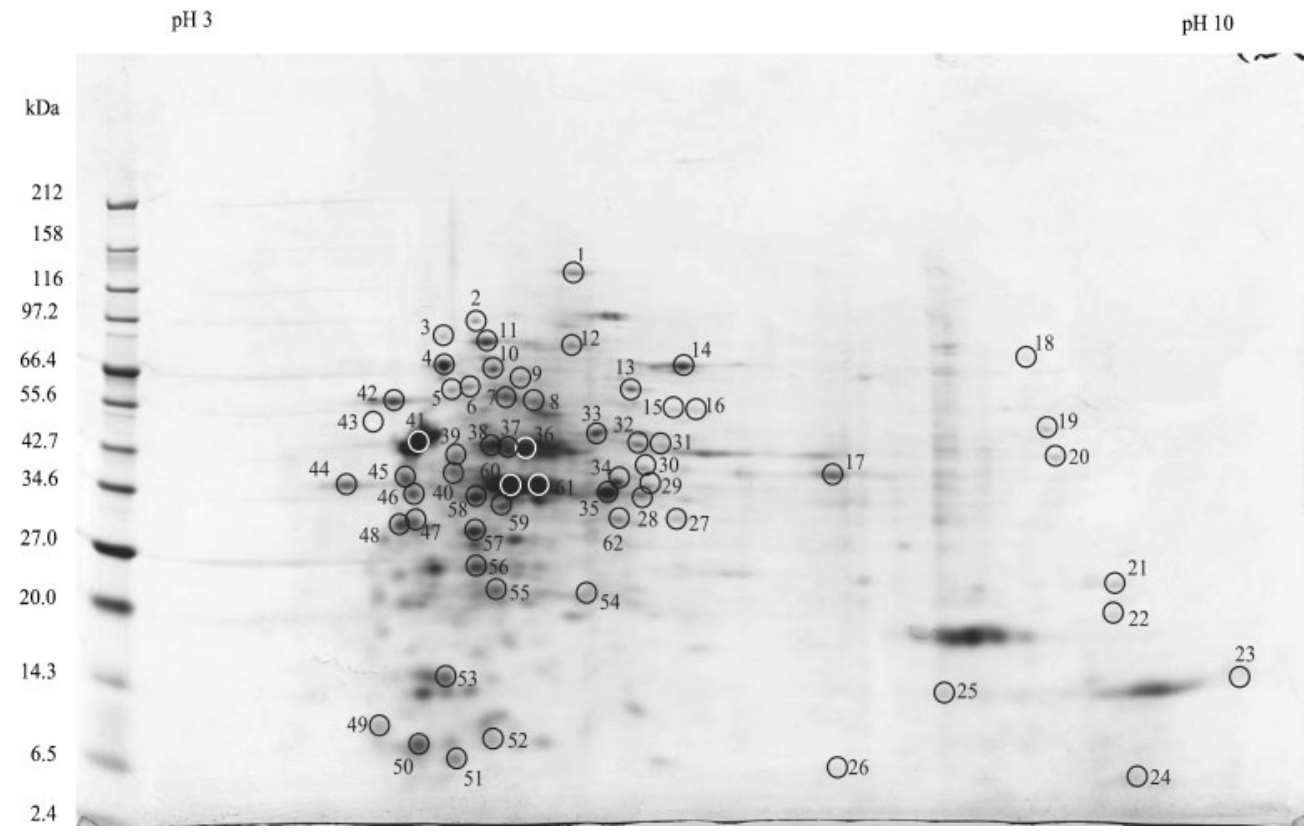

Fig. 3. Immunoreactive cell wall proteins from C. difficile M9. Protein $(50 \mu \mathrm{g})$ was separated by $2 \mathrm{DE}$ and stained with colloidal Coomassie blue. The gel was compared carefully with the Western blots (Fig. 2) and immunoreactive proteins (indicated by circles) were picked for MS/MS analysis. Individual spots are numbered, and in many cases were recognized by sera from more than one patient (Table 1 and Supplementary Table S1, available with the online journal). Molecular masses in kDa are indicated on the left and the $\mathrm{pH}$ is indicated at the top. The identities of the labelled protein spots are given in Table 1 and Supplementary Table S1.

2DE of cell wall proteins stained with Coomassie blue. The circled spots are those that were immunoreactive against one or more patients. These immunoreactive proteins were picked from the stained gel and subjected to MS analysis to determine their identity. A total of 62 protein spots was identified, revealing the identities of 42 different proteins. Eleven of these proteins were predicted to be cell wall- or membrane-associated and these are detailed in Table 1. The remaining 31 proteins were also identified, and were not predicted by SignalP to be secreted. The complete dataset, including proteins predicted to reside in the cytoplasm, is given in Supplementary Table S1, available with the online journal. Each of the six patient sera recognized a discrete pattern of $C$. difficile proteins; between 6 and 31 protein spots were visible on each Western blot (Fig. 2a-e). Some of these proteins were common among the patients, whilst others were unique to a single patient. The patterns of immunoreactive proteins recognized by the antibodies from the patients that suffered a single episode of CDAD (Fig. 2a-d) were not significantly different from those from the two patients who suffered relapsing infections (Fig. 2e, f). The sera of patients 1 and 2 appeared to recognize fewer proteins than patients 3-6.

Patients 2-6 recognized the high-molecular-mass SLP, whilst patients $1,2,4,5$ and 6 recognized the lowmolecular-mass SLP. Thus, all patients recognized at least one of the two subunits of the SLP. Four of the patient sera contained antibodies against both the high- and lowmolecular-mass SLPs, and five contained antibodies to a related protein CD2791 (uncharacterized proteins are named according to their designation (Sebaihia et al., 2006) (http://www.sanger.ac.uk/Projects/C_difficile/). These were by far the most common antigens recognized, but other antigens recognized by the serum of more than one patient included CD2787 (also termed Cwp84; Karjalainen et al., 2001), the chaperones DnaK and HtpG (see Supplementary Table S1 available with the online journal) and two components of $\mathrm{ABC}$ transporters. Most immunoreactive proteins $(55 \%)$ were only recognized by the serum of one patient, although in some instances the same protein was detected in multiple spots on the same gel (e.g. patient 5, spots 31 and 32, or spots 28 and 35). In total, five members of the protein family related to SlpA (CD2791, CD2786, CD2787, CD2767 and $\mathrm{CD} 1047)$ were recognized, indicating that these proteins are expressed in vivo during infection.

\section{Conclusions}

In this study, we found a large number of $C$. difficile proteins that are reactive against human sera. Whilst all sera samples contained antibodies to one or both components of the SLP, the spectrum of responses to other antigens varied among patients. Other antigens recognized included FliC, Cwp84 and several other surface- 
Table 1. Identities of $C$. difficile immunoreactive proteins predicted to be surface localized

Proteins were identified by MS/MS analysis. The spot numbers are those referred to in Fig. 3. A full list of all 62 proteins identified and further data on all proteins is given in Supplementary Table S1 (available with the online journal). HMM, High molecular mass; LMM, low molecular mass.

\begin{tabular}{|lcll|}
\hline Protein & Spot & Patient & Genome ID \\
\hline Cwp 2 & 14 & $1,2,4,5,6$ & CD2791 \\
Cwp 5 & 13 & 1 & CD2786 \\
Cwp 84 & 8 & $1,2,6$ & CD2787 \\
Cwp 19 & 19 & 3 & CD2767 \\
Cwp 18 & 62 & 6 & CD1047 \\
SlpA & 3 & 3 & CD2793 \\
HMM SLP & 39 & 6 & CD2793 \\
HMM SLP & 45 & $3,4,5$ & CD2793 \\
HMM SLP & 46 & 5 & CD2793 \\
HMM SLP & 47 & 5 & CD2793 \\
HMM SLP & 48 & $3,4,5$ & CD2793 \\
HMM SLP & 49 & 6 & CD2793 \\
HMM SLP & 50 & 6 & CD2793 \\
HMM SLP & 51 & 2 & CD2793 \\
LMM SLP & 60 & $1,2,4,5,6$ & CD2793 \\
LMM SLP & 61 & 2,6 & CD0239 \\
LMM SLP & 40 & 6 & CD2672 \\
FliC, flagellin & 58 & 4 & CD0873 \\
AppA, oligopeptide ABC transporter & 42 & $1,2,5,6$ & CD1467 \\
ABC transporter, substrate binding lipoprotein & 44 & $2,3,6$ & \\
ABC transporter, permease protein & 26 & 5 & \\
\hline
\end{tabular}

associated proteins that were common to several patients. A number of these proteins were also found to be seroreactive in an earlier study (Pechine et al., 2005). In that study, four defined $C$. difficile cell-surface antigens were analysed: FliC, FliD, Cwp66 and Cwp84. The majority of patients were found to be seropositive for all antigens, but interestingly 1 or 2 patients, out of a cohort of 17 tested, were seronegative for one or more antigen. In our study, we screened all cell wall proteins for their reactivity to human sera, rather than determine the titres against a few defined antigens. In this way, we showed that some human sera contain antibodies against hitherto-uncharacterized cell wall proteins. Our study complements others where human immune responses to specific $C$. difficile proteins have been analysed. In our study, we did not expect to analyse serum responses to $\mathrm{TcdA}$ or $\mathrm{TcdB}$, as these are secreted proteins not present on the cell wall. It was not possible for us to include a cohort of normal individuals without a history of CDAD. However, the variability in response to $C$. difficile antigens found here suggests that it would be worthwhile conducting a larger prospective study similar to that reported previously (Kyne et al., 2000), but incorporating proteomic approaches to characterize changes in serum responses following infection.

\section{ACKNOWLEDGEMENTS}

This work was funded by a BBSRC studentship to A. W.

\section{REFERENCES}

Bartlett, J. G. (2007). Clostridium difficile: old and new observations. J Clin Gastroenterol 41 (Suppl. 1), S24-S29.

Calabi, E., Ward, S., Wren, B., Paxton, T., Panico, M., Morris, H., Dell, A., Dougan, G. \& Fairweather, N. (2001). Molecular characterization of the surface layer proteins from Clostridium difficile. Mol Microbiol 40, 1187-1199.

Cloud, J. \& Kelly, C. P. (2007). Update on Clostridium difficile associated disease. Curr Opin Gastroenterol 23, 4-9.

Drudy, D., Calabi, E., Kyne, L., Sougioultzis, S., Kelly, E., Fairweather, N. \& Kelly, C. P. (2004). Human antibody response to surface layer proteins in Clostridium difficile infection. FEMS Immunol Med Microbiol 41, 237-242.

Drudy, D., Quinn, T., O'Mahony, R., Kyne, L., O'Gaora, P. \& Fanning, S. (2006). High-level resistance to moxifloxacin and gatifloxacin associated with a novel mutation in $\operatorname{gyrB}$ in toxin-A-negative, toxin-Bpositive Clostridium difficile. J Antimicrob Chemother 58, 1264-1267.

Hennequin, C., Porcheray, F., Waligora-Dupriet, A., Collignon, A., Barc, M., Bourlioux, P. \& Karjalainen, T. (2001). GroEL (Hsp60) of Clostridium difficile is involved in cell adherence. Microbiology 147, 87-96.

Hennequin, C., Janoir, C., Barc, M.-C., Collignon, A. \& Karjalainen, T. (2003). Identification and characterization of a fibronectin-binding protein from Clostridium difficile. Microbiology 149, 2779-2787.

Just, I. \& Gerhard, R. (2004). Large clostridial cytotoxins. Rev Physiol Biochem Pharmacol 152, 23-47.

Karjalainen, T., Waligora-Dupriet, A.-J., Cerquetti, M., Spigaglia, P., Maggioni, A., Mauri, P. \& Mastrantonio, P. (2001). Molecular and genomic analysis of genes encoding surface-anchored proteins from Clostridium difficile. Infect Immun 69, 3442-3446. 
Kyne, L., Warny, M., Qamar, A. \& Kelly, C. P. (2000). Asymptomatic carriage of Clostridium difficile and serum levels of IgG antibody against toxin A. N Engl J Med 342, 390-397.

Pechine, S., Gleizes, A., Janoir, C., Gorges-Kergot, R., Barc, M.-C., Delmee, M. \& Collignon, A. (2005). Immunological properties of surface proteins of Clostridium difficile. J Med Microbiol 54, 193-196.

Poxton, I. R., McCoubrey, J. \& Blair, G. (2001). The pathogenicity of Clostridium difficile. Clin Microbiol Infect 7, 421-427.

Qazi, O., Sesardic, D., Tierney, R., Soderback, Z., Crane, D., Bolgiano, B. \& Fairweather, N. (2006). Reduction of the ganglioside binding activity of the tetanus toxin $\mathrm{HC}$ fragment destroys immunogenicity: implications for development of novel tetanus vaccines. Infect Immun 74, 4884-4891.

Sebaihia, M., Wren, B. W., Mullany, P., Fairweather, N. F., Minton, N., Stabler, R., Thomson, N. R., Roberts, A. P., Cerdeno-Tarraga, A. M. \& other authors (2006). The multidrug-resistant human pathogen Clostridium difficile has a highly mobile, mosaic genome. Nat Genet 38, 779-786.

Tasteyre, A., Barc, M. C., Karjalainen, T., Dodson, P., Hyde, S., Bourlioux, P. \& Borriello, P. (2000). A Clostridium difficile gene encoding flagellin. Microbiology 146, 957-966.

Voth, D. E. \& Ballard, J. D. (2005). Clostridium difficile toxins: mechanism of action and role in disease. Clin Microbiol Rev 18, 247-263.

Waligora, A. J., Hennequin, C., Mullany, P., Bourlioux, P., Collignon, A. \& Karjalainen, T. (2001). Characterization of a cell surface protein of Clostridium difficile with adhesive properties. Infect Immun 69, 2144-2153.

Wright, A., Wait, R., Begum, S., Crossett, B., Nagy, J., Brown, K. \& Fairweather, N. (2005). Proteomic analysis of cell surface proteins from Clostridium difficile. Proteomics 5, 2443-2452. 